Whrte DJ, ed. Cyclosporin A: Proceedings of the International Symposium, Cambridge Amsterdam: Elsevier Biomedical Publishers; 1982:354.

2. Kahan BD. Ried M, Newbenger J. Pharmacokinetics of cyclosporine in human renal transplantation. Transplant Proc. 1983;15:446-53.

3. WHITE DJ. Cyclosporin A: clinical pharmacology and therapeutic potential. Druge 1982;24:322-34.

4. KAHAN BD. Meeting Report: the First International Congress on Cyclosporine: Houston, Texas: May 16-19, 1983. Dial Transplant. 1983;12:620-30.

5. VON WILlebrand E. Hayry P. Cyclosporin-A deposits in renal allografls. Lencet. 1983;2:189-92.

6. Sibley RK, Ferguson RM, Sutherland DE, Simmons RL, NAiRIAN JS. Morphology of cyclosporine nephrotoxicity and of acute rejection in cyclosporine-prednisone immunosuppressed renal allograft recipients. Transplant Proc. 1983. (In press).

7. Wagner E. Pichylmayr R. Worigeit K. KLempnauer J, BunzenDAHL $H$, LAUCHART W. Differentiation between rejection and cyclosporin A nephrotoxicity by monitoring interstitial pressure in human renal allografts. Transplant Proc. 1983;15:489-92.

8. Hamilton DV, Calne RY. Evans DB, Henderson RG. Thitu S, WhrTE DJ. The effect of long-term cyclosporin $A$ on renal function [Letter]. Lancet. 1981;1:1218-9.

9. Najarian JS, Ferguson RM, Sutherland DE, Rynasiewicz JT, Simmons RL. A prospective trial of the efficacy of cyclosporine in renal transplantation at the University of Minnesota. Transplant Proc. 1983;15:438-41.

10. Hamilton DV, EVANS DB, ThIRU S. Toxicity of cyclosporin A in organ grafting. In: WhrTE DJ, ed. Cyclosporin A: Proceedings of the Intemational Symposium, Cambridge. Amsterdam: Elsevier Biomedical Publishers; 1982:393-411.

11. Venkatachalam MA. Pathology of acute renal failure. In: Brenner B, SteIN J, eds. Chronic Renal Failure. New York: Churchill-Livingstone; 1981:79-107.

12. Farnsworth A, Hall BM, Kirwan P, et al. Pathology in renal transplant patients treated with cyclosporin A. Transplant Proc. 1983. (In press).

13. Mihatsch MJ, Olivieri W, Marbet U, Thiel G, Harder F, ZolLINGER HU. Giant mitochondria in renal tubular cells and cyclosporin A [Letter]. Lancet. 1981;1:1162-3.

14. Shulman H, Striker G, Deeg HJ, Kennedy M, Storb R, Thomas ED. Nephrotoxicity of cyclosporin $A$ after allogeneic marrow transplan- tation: glomerular thromboses and tubular injury. $N$ End $J$ Med. 1981;305:1392-5.

15. Lejthner C. Sinzinger H, Pohanka E, Schwarz M, Kretschmer G, SYRE G. Recurrence of haemolytic uraemic syndrome trizgered by cyclosporin A after renal transplantation [Letter]. Lencer. 1982;1:1470.

16. Greenbeno A, Egel J, Thompson M, et al. Renal failure in heart transplant patients receiving cyclosporin A [Abstract]. Clin Res. 1983;31:429A.

17. Joss DV, BARrett AJ, Kendra JR, Lucas CF. Desal S. Hypertension and convulsions in children receiving cyclosporin A [Letter]. Lencet. 1982;1:906.

18. Adu D, TURney J, Michael J, MCMaster P. Hyperkalhemia in cyo losporin-treated renal allograft recipients. Lencet. 1983;2:370-2

19. Stiller CR, KeOWN PA, Sinclair NR, Ulan RA. Immune respone$a$ and pharmacokinetics in the human renal allograft recipient treated with cyclosporin A. In: WHTrE DJ, ed. Cyclosporin A: Proceedings of the International Symposium, Cambridge Amsterdam: Elsevier Biomedical Publishers; 1982:379-86.

20. Kennedy MS, Deeg HJ, Siegel M, Crowley JJ, Store R. Thomas ED. Acute renal toxicity with combined use of amphotericin B and cyciosporine after marrow transplantation. Transplantation. 1983;35:211-5.

21. Ferguson RM. Sutherland DE, Simmons RL, Najarian JS. Ketoconazole, cyclosporin metabolism, and renal transplantation [Letter]. Lencet. 1982;2:882-3.

22. Whiting PH, Thomson AW, Blair JT, Simpson JG. Experimental cyclosporin A nephrotoxicity. Br J Exp Pathol. 1982;63:88-94.

23. RYFFEL B. Experimental toxicological studies with cyclosporin A. In: White DJ, ed. Cyclosporin A: Proceedings of the International Sympo sium, Cambridge. Amsterdam: Elsevier Biomedical Publishers; 1982:4575.

24. Baxter CR, Duggin GG, Willis NS, Hall BM, Horvath JS, TiLLER DJ. Cyclosporin A-induced increases in renin storage and release Res Commun Chem Pathol Pharmacol. 1982;37:305-12.

25. KIRWAN PD, BAXTER CR, DUGGIN GG, et al. Giant mitchondria renal transplant biopsy, and cyclosporin A [Letter]. Lencet. 1981;2:146.

26. Cunningham C. Burke MD, Whiting PH, Simpson JG, Wheatley DN. Ketoconazole, cyclosporin, and the kidney [Letter]. 1982;2:1464.

27. Shiel AGR, HALl BM, TILLER DJ, et al. Australian trial of cyciosporin A in cadaveric donor transplantation. Transplant Proc 1983. (In press).

01983 American College of Physicians

\title{
After 20 Years, Liver Transplantation Comes of Age
}

AfTer 20 years as an experimental procedure, orthotopic liver transplantation for patients with advanced hepatic disease has come of age $(1,2)$. Survival statistics from the four centers with the most experience suggest that the 1-year survival for children having a hepatic transplant should exceed $70 \%$, whereas that for adults should exceed $50 \%$ and may, with more care given to the choice of candidates and experience, approach the level of success being achieved in children (3-7). Late deaths among transplant recipients occurring after the first year of survival are unusual and attrition after 1 year of survival actually approaches that seen in the general population (2). The longest known living hepatic transplant survivor is alive, 15 years after the original procedure.

Encouraged by these results, several hepatic transplantation programs have been started or reopened. In the United States, in addition to the program at the University of Pittsburgh, liver transplantation programs presently exist at the University of Minnesota, the University of Tennessee, the University of California (Davis), Harvard University (Massachusetts General Hospital), and Tufts University. Additional programs are likely to develop at several other university health centers, including the University of California (San Diego), University of Wiscon- sin, and the Medical College of Virginia, and in Toronto and Montreal in Canada. Abroad, active programs already exist in Cambridge, England, and in Holland, East Germany, and West Germany; others are being developed in London, England, and in France, Spain, Italy, China, and Taiwan.

Two factors have contributed to the recent success of orthotopic liver transplantation: the availability and use of cyclosporine; and the joint involvement of medical and surgical teams in the evaluation, selection, and pre- and postoperative care of hepatic transplant patients.

The discovery of cyclosporine, a potent immunosuppressive agent having little or no bone marrow toxicity, has revolutionized not only hepatic but all forms of immunosuppression therapy used for organ transplantation (8-13). Its development was particularly important because of the time constraints of liver preservation, the recipient's urgent need for the procedure, and the absolute unavailability of living related donors. Moreover, matching donors and recipients at the HLA, A, B, and Dr loci of the recognized histocompatibility antigens has been impractical because of the limited number of donor organs available. Similarly, the necessity for a patient to receive a transplant despite anti-donor $\mathrm{T}$ warm antibod- 
ies will persist because of the limited number of donor organs available and the urgent need to do the transplant in a given candidate (2). These difficulties can be avoided in renal transplantation because of the larger pool of donor organs (two from each cadaver and one from each living related donor), the existence of an acceptable alternative renal support system (peritoneal and hemodialysis), and the cold ischemia time tolerated by the kidney to be transplanted that allows for successful engraftment in a recipient thousands of miles and hours away from the donor.

In addition to time constraints and an overall lack of donor organs, another problem that limits transplantation teams from better matching donors and recipients is the need to have a donor organ smaller than that of the recipient, so that it can physically be implanted and the abdominal wound closed (2). Thus the use of HLA and other means of matching donors and recipients is not available for liver transplantation. As a result, more powerful immunosuppressant agents such as cyclosporine are required for successful hepatic transplantation than are required for nonhepatic organs.

The second factor has been the commitment of experienced and independent hepatologists working with hepatic surgeons in the several largest transplant programs (14). Thus both at Cambridge and Pittsburgh, hepatologists as well as surgeons are involved in the liver transplant program. Such cooperation and interaction between disciplines has contributed to a better selection of transplant candidates and the earlièr recognition and management of postoperative complications such as sepsis, rejection, and liver failure $(14,15)$. Equally important is the identification of patients with better and poorer prognoses after hepatic transplantation, and of the clinical situations that predict operative or postoperative difficulty (such as portal vein thrombosis, presence of coexisting nonhepatic medical and surgical disease, the presence of biliary or extrahepatic sepsis, and hepatitis B surface and e antigenemia) (15).

More important than simple survival statistics is the quality of life of patients after successful liver transplantation. Few data are available that address this issue (15). Anecdotal information shows that successful pregnancy and parenthood is possible after liver transplantation; a return to active life and gainful employment is achieved in as many as $85 \%$ of adults receiving transplants; and children who have successful transplants return to school and have normal growth and pubertal development.

The National Institutes of Health recently held a consensus conference in Bethesda, Maryland, on liver transplantation. After a thorough evaluation of the data presented by experts in liver disease both from the United States and abroad, the conference panel concluded that orthotopic liver transplantation is therapeutic for some forms of chronic advanced liver disease and should be more broadly applied; should undergo continuing evaluation; and should be done at a limited number of medical centers that have adequate support facilities and a trained staff; and that continued education of physicians who can recognize and treat liver diseases, and surgeons who are capable of doing the procedure, should be encouraged.

The important issues of the cost and payment of the procedure were not addressed by the panel. However, these matters will be addressed by the Office of Health Technology Assessment as part of its upcoming reimbursement recommendations due in late August 1983. Costs of the procedure can differ. At the University of Pittsburgh, for example, costs from initial evaluation to discharge from hospital after transplantation is between $\$ 55000$ to $\$ 85000$, depending on the duration of time spent in the intensive care unit after the operation (14). In contrast, the units at the University of Minnesota and in Massachusetts have estimated the cost of the procedure in their areas to range between $\$ 200000$ and $\$ 250000$ per patient (16).

However; the cost of each procedure will tend to decline as the number done increases (which may explain, in part, the differences in estimated costs at various locations in the United States). Also, with increasing experience at a given institution, the entire process of patient selection, operative procedure, and postoperative care becomes standardized and more efficient. Series data on liver transplantation rather than isolated anecdotal information are becoming available that will serve as the basis on which modifications of existing programs and new programs can build.

Available data strongly suggest that groups that do the procedure with some regularity tend to have the best results (3-7). This result reflects the natural course of events with any new operative procedure. Clinical decision making is enhanced and patient care improved as one's experience expands.

The development of a well planned registry of liver transplantation procedures should be encouraged and developed. Such a registry would maximize data collection on liver transplantation and serve to crystallize our understanding of this expanding area of interdisciplinary clinical experience. In addition, the registry would facilitate the development of protocols for the broader application of liver transplantation to patients with hepatic conditions not yet deemed appropriate for the procedure. Clearly, a central depository for such data at an active liver transplantation center would lead to the most efficient expansion of new ideas and information on techniques, indications, and survival statistics associated with liver transplantation.

Finally, the livers of recipients, removed during transplantation, are a unique and valuable resource that should be made available to qualified investigators for research directed toward a better understanding of liver diseases, hepatic physiology, and human biochemistry in general. Thus, effort expended to save these organs and make them available to a wide spectrum of investigators interested in human disease not only best serves our patients but also serves society at large. (DAVID H. VAN ThIEL, M.D.; ROBERT R. SChaDE, M.D.; and ThOMAS E. STARZL, M.D., PH.D.; University of Pittsburgh School of Medicine; Pittsburgh, Pennsylvania)

ACKNOWLEDGMENTS: Grant support: in part by a grant from the Gas- 
troenterology Medical Foundation of Southwestern Pennsylvania, and grants AM 17260, AM 07772, AM 29961, and AM 30183 from the National Institutes of Health.

\section{References}

1. Starzl TE, Marchioro TL, Vonkaulla KN, et al. Homotransplantation of the liver in humans. Surg Gynecol Obstet. 1963;117:659-79.

2. Starzi TE, Iwatsuki S, Van Thiel DH, et al. Evolution of liver transplantation. Hepatology. 1982;2:614-36.

3. Starei TE. IWAtsuki S, SHAW BW JR, e al. Consensus conference report on liver transplantation. Hepatology. 1984 (In press).

4. Rolles K. CAlNe RY. Orthotopic liver transplantation 1968-1983: the Cambridge experience. Hepatology. 1984 (In press).

5. PichlmayR R. Consensus development conference on liver transplantation: experience with liver transplantation. Hepatology. 1984 (In press).

6. Krom RAF, Girs CH. Houthoff JH, et al. Orthotopic liver transplantation in Groningen (The Netherlands) 1979-1983. Hepatology. 1984 (In press).

7. SснАлsснміDT BF. Experience with liver transplantation. Hepatology. 1984 (In press).

8. Borel JF, Feurer C, Gubler HU, Stahelin H. Biological effects of cyclosporin A: a new antilymphocytic agent. Agents Actions. 1976:6:468-75.

9. Borel Jf, Feurer C. Magnce C, Stahelin H. Effects of the new antilymphocytic peptide cyclosporin $A$ in animale Immunologe. 1977;32:1017-25.

10. Kostaxis AJ, Whrte DJG, Calne RY. Prolongation of rat heart allo graft survival by cyclosporin A.IRCS Med Sci. 1977;5:280.

11. Green CJ, Allison AC. Extensive prolongation of rabbit kidney allo graft survival after short term cyclosporin A treatment. Lancec 1978;1:1182-3.

12. CAlNe RY, White DJH, ThiRu S, et al. Cyclosporin A in patient receiving renal allografts from cadaver donors. Lancec. 1978;2:1323-7.

13. Calne RY. Rolles K. Whtte DJG, et al. Cyclosporin A initially a the only immunosuppreseant in 34 patients of cadaveric organs: 32 kidneys, 2 pancreases and 2 livers. Lencer. 1979;2:1033-6.

14. Van Thiel DH. Schade RR, Starzl TE. Iwatsuki S. Shaw BW JR, GAVAler JS, DugAs M. Liver transplantation in adults. HepataloBy. 1982;2:637-40.

15. Van Thiel DH, Schade RR, Gavaler JS, Shaw BW, JR, Iwatsur! S, Starzi TE. Medical aspects of liver transplantation. Hepetology. 1984. (In press).

16. FINAL REPORT OF THE TASK FORCE ON LIVER TRANSPLANTATION N Massachusetrs. Submitted to the Commissioner of Public Health, May, 1983. Available from Joan M. Gorga, Special Assistant for Policy and Planning, Department for Public Health, 600 Washington Street. Boston, MA 02111

01983 American College of Physicians

\section{New Goals for Education in Geriatric Medicine}

How CAN PHYSICIANS be prepared to fulfill the healthcare needs of older persons in the community, in the hospital, and in the long-term care institution? The Executive Council of the Association of American Medical Colleges has recently published a set of guidelines by which medical colleges can measure their educational efforts in geriatric medicine (1). These guidelines represent the wisdom of persons representing " . . . almost 90 percent of the nation's academic medical centers" (1) and provide an outline of the breadth of issues and domains of knowledge relevant to care of the elderly. The recommendations extend those of the Institute of Medicine's report on geriatric medical education published 5 years ago (2) and certainly will serve as a resource for academic programs in geriatric medicine.

Up to now, training in geriatric medicine, in general, has used intuitively derived learning objectives, and the Associaton's guidelines restate the prevailing trinity of geriatric medicine: attitude (poor attitudes to old persons compromise their care), demography (the growing numbers of old persons define the need for geriatric medicine), and leadership (physicians must learn to direct the geriatric health-care team). This dogma should be further examined.

The Association's report addresses the need to ensure the development of proper attitudes toward the elderly by physicians. Studies show that the relation between therapist and patient is critically important to successful care (3). However, are positive attitudes more important in the care of old patients than they are in the care of younger patients? Perhaps of greater relevance, geriatric medical education may assert a balance between caring and curing in medical education. Furthermore, the new report properly emphasizes the different spectrum of diseases, the frequency of multiple diseases, the altered pre- sentation of disease, and particularly, the need to extend our knowledge of the pathogeneses of the diseases of aging.

A frequently repeated raison d'etre for geriatrics is the demographic imperative. Today, $11 \%$ of Americans are over 65 years of age and this percentage will rise as we enter the 21 st century. Geriatrics has been justified not only by the growing age of the population, but because the elderly occupy nearly half of the beds in acute care hospitals and $86 \%$ of beds in long-term care institutions. More important than the numbers, however, is the fact that geriatricians deal with chronic illness. Chronic diseases are the challenge for medicine in the coming years. Geriatric medicine heralds the health care of the $21 \mathrm{st}$ century, much as Garrod, at the turn of the 20th century, recognized the seminal importance of the inborn errors of metabolism that foreshadowed the revolution in the molecular basis of human disease. Geriatrics is concerned with patients with multiple and chronic diseases that require continuing care. Today, most of our patients, old and young, have chronic diseases. This fact and the need to view chronic disease within the perspective of a life span and in its interaction with aging physiological systems are perhaps the most important lessons being learned from geriatrics.

Chronically and multiply impaired elderly patients need services beyond the realm of traditional medical practice. For this reason, the concept of a team (including physicians, nurses, social workers, nutritionists, podiatrists, and others) that together cares for the patient has emerged. The physician - the professional with the greatest training and most clout in the health professions-has been nominated by some, usually physicians, to be team leader or case manager. The report by the Association of American Medical Colleges suggests pre- 